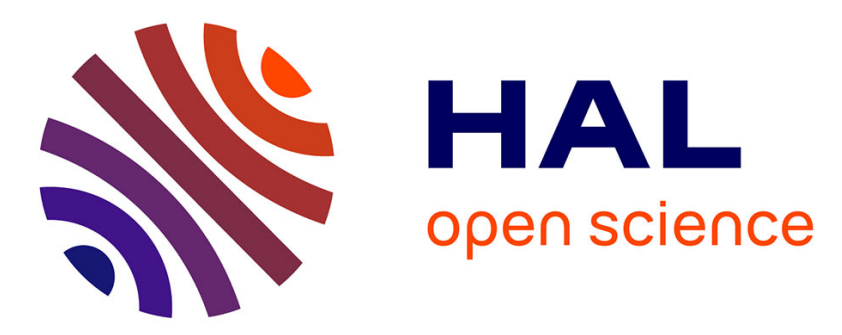

\title{
Measurement of implant deployment and related forces in kyphoplasty by percutaneous approach
}

\author{
F. Bolzinger, J.F. Oglaza, A. Krüger, Pascal Swider
}

\section{To cite this version:}

F. Bolzinger, J.F. Oglaza, A. Krüger, Pascal Swider. Measurement of implant deployment and related forces in kyphoplasty by percutaneous approach. Clinical Biomechanics, 2014, vol. $29\left(\mathrm{n}^{\circ} 4\right)$, pp. 463-467. 10.1016/j.clinbiomech.2014.01.001 . hal-01585301

\section{HAL Id: hal-01585301 https://hal.science/hal-01585301}

Submitted on 11 Sep 2017

HAL is a multi-disciplinary open access archive for the deposit and dissemination of scientific research documents, whether they are published or not. The documents may come from teaching and research institutions in France or abroad, or from public or private research centers.
L'archive ouverte pluridisciplinaire HAL, est destinée au dépôt et à la diffusion de documents scientifiques de niveau recherche, publiés ou non, émanant des établissements d'enseignement et de recherche français ou étrangers, des laboratoires publics ou privés. 


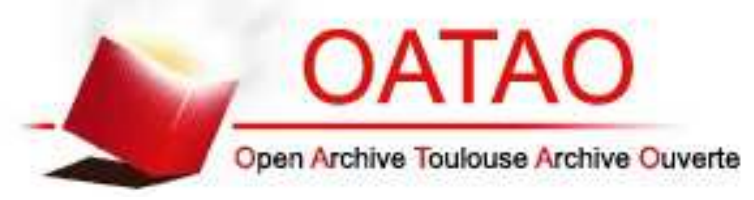

\section{Open Archive TOULOUSE Archive Ouverte (OATAO)}

OATAO is an open access repository that collects the work of Toulouse researchers and makes it freely available over the web where possible.

This is an author-deposited version published in : http://oatao.univ-toulouse.fr/ Eprints ID : 18157

To link to this article : DOI: $10.1016 /$ j.clinbiomech.2014.01.001 URL : http://dx.doi.org/10.1016/j.clinbiomech.2014.01.001

To cite this version : Bolzinger, F. and Oglaza, J.F. and Krüger, A. and Swider, Pascal Measurement of implant deployment and related forces in kyphoplasty by percutaneous approach. (2014) Clinical Biomechanics, vol. 29 ( $\left.\mathrm{n}^{\circ} 4\right)$. pp. 463-467. ISSN 0268-0033

Any correspondence concerning this service should be sent to the repository administrator: staff-oatao@ listes-diff.inp-toulouse.fr 


\title{
Measurement of implant deployment and related forces in kyphoplasty by percutaneous approach
}

\author{
F. Bolzinger ${ }^{\text {a,b }}$, J.F. Oglaza ${ }^{\text {b }}$, A. Krüger ${ }^{\text {c }}$, P. Swider ${ }^{\text {a,* }}$ \\ a IMFT UMR 5502, University of Toulouse, 2 allées C. Soula, 31400 Toulouse, France \\ ${ }^{\mathrm{b}}$ VEXIM SA, 75 rue Saint Jean, 31130 Balma, France \\ ' Department of Trauma-, Hand- and Reconstructive Surgery, University Hospital Giessen and Marburg GmbH, Location Marburg, Baldingerstraße, D-35043 Marburg, Germany
}

\section{Keywords:}

Kyphoplasty surgery

Instrumented ancillary

Deployable implant

Experimental method

Analytical model

\section{A B S T R A C T}

Background: The treatment of osteoporotic vertebral compression fractures using a transpedicular approach and cement injection has grown significantly over the last two decades.

Methods: The aim was to study the deployment of an implant dedicated to the vertebral augmentation by percutaneous approach (kyphoplasty). Its kinematics and the related forces have been investigated. A theoretical model of deployment has been proposed and the ancillary was instrumented with strain gauges and Hall effect sensors to measure kinematics and force in the deployment actuator (tensile rod). The methodology was first evaluated ex-vivo in a test-bench with boundary conditions monitored by a tensile machine. Then, a cadaver study was carried out in three lumbar and thoracic vertebral segments of normal and osteoporotic spines.

Findings: The relationships between ancillary internal forces, deployment, and cranio-caudal pushing force have been obtained. The test-bench experiment showed quasi-proportional relationship between force distribution and kinematics during the deployment. Ex-vivo cranio-caudal pushing forces were measured. Cadaver studies showed cranio-caudal pushing forces comprised between $100 \mathrm{~N}$ and $200 \mathrm{~N}$. These forces were dependent upon the implant location in the vertebral body and bone stock.

Interpretation: The methodology was related to the analysis of load distribution and kinematics of a deployable implant for vertebral augmentation. The ancillary instrumentation contributed to the objective quantification of the surgical technique. The cadaver study in normal and osteoporotic spines exhibited the role of bone properties and implant location in implant deployment. This pilot study showed a methodology to improve the kyphoplasty surgery and patient comfort in clinical routine.

\section{Introduction}

The treatment of osteoporotic vertebral compression fractures using a transpedicular approach and cement injection has grown significantly over the last two decades. Reducing fractures in combination with improving sagittal kyphosis is supposed to show better long-term effects. Benefits of an anatomic reduction of fractured vertebrae are assistance to lung vital capacity and the risk reduction of adjacent fractures. Several techniques are proposed to restore vertebral height and improve sagittal alignment and they are mainly subdivided in vertebroplasty and kyphoplasty techniques. Both include a percutaneous approach and injection of bone cements into affected vertebral bodies. They are commonly used in the treatment of trauma and painful osteoporotic vertebral fractures.

\footnotetext{
* Corresponding author at: IMFT UMR 5502 - Biomechanics, 2 allées C. Soula, 31400 Toulouse cedex, France.

E-mail address: pascal.swider@univ-tlse3.fr (P. Swider).
}

Initially, the technique of cement injection was described by (Galibert et al. 1987) and named vertebroplasty, the introduction of balloon kyphoplasty followed latterly (Wong et al. 2000). In this technique, a void in the vertebral body is created by using an inflatable balloon prior to cement injection. To limit the loss of height restoration, a deployable device (SpineJack ${ }^{\circledR}$ by Vexim SA, Toulouse, France) was designed to remain inside the vertebral body during cement injection (Knowlton 2009). One rational of the SpineJack ${ }^{\circledR}$ is the possibility to direct reduction forces in the cranio-caudal direction whereas in Balloon Kyphoplasty "spherical" forces are deployed. Surgical treatments (using both procedures) have been rising significantly.

We hypothesized that the kinematics of the actuator and its driving force were correlated with the implant deployment and its pushing force during vertebral height restoration. The objective quantification of kinematics and induced forces might help into the intra-operative guidance of vertebral augmentation. The ancillary of the implant was instrumented to measure the kinematics of the actuator and the driving force. First, the methodology was evaluated ex-vivo in a test bench. The boundary conditions of deployments and forces were controlled. Then, a cadaver study in normal and pathological spines allowed evaluating the methodology. 


\section{Methods}

\subsection{Description of the surgical technique}

Access into the vertebrae using the SpineJack ${ }^{\circledR}$ device is similar to balloon kyphoplasty. After insertion of two guide wires, the pedicle and vertebral body are reamed and a template under fluoroscopy locates the later position of the implant. Then the implant replacing the template is opened in the cranio-caudal direction. Finally, bone cement is injected into the vertebral body.

\subsection{Description of the measurement devices}

The device is described in Fig. 1. The folding implant (a) located in the vertebral body (b) was actuated by the tensile rod (c) guided by a tube through the pedicles. The rotation of the ancillary handle (d) induced the rod stroke $s$ by means of a helical joint. The deployment mode had two-symmetry axis and the governing law $D(s)$ is represented by Eq. (1) assuming that the structure was rigid except for the plastic hinge (c). Equation was obtained by using trigonometric relationships governing one quarter of the implant. The length $l$ of each of the four arms was fixed and $\alpha_{0}$ was the initial angle of the arms with the horizontal axis.

$D(s)=\sqrt{l^{2}-\left(l \cos \alpha_{0}-s\right)^{2}}-l \sin \alpha_{0}$

The axial force $F_{a}$ applied by the tensile rod induced plastic strains in localized hinge of the four arms and forced the implant deployment. The plateau exerted the cranio-caudal pushing force $F_{p}$ onto cancellous bone. The relationship between $F_{a}$ and $F_{p}$ was expressed by Eq. (2). The coefficient $r(s)$ based upon experimental data was intended to attenuate the available force available if the energy lost in the plastic hinge was showing a significant role. Its use has not been necessary in the presented study.

$F_{p}=F_{a}[1-r(s)] \cdot \sqrt{\left(\cos \alpha_{0}-s / l\right)^{-2}-1}$

The torque $C_{h}$ on the handle (d) was computed by using the modified empiric Eq. (3) (ISO 16047, 2005-2007) involving the rod diameter $d$, its thread $t$ and the friction coefficient $\mu$. The ancillary was maintained stable by the clinician by using the fixed handle (e).

$C_{h}=(0.583 \mu d+t / 2 \pi) \cdot F_{a}$
The axial force $F_{a}$ was measured by strain gauges (f) in full-bridge located on the tensile rod. The rotation of the handle was measured by an effect hall sensor glued on the ancillary handle (e) and facing 8 rotating magnets $(\mathrm{g})$. A pulse counter allowed the handle rotation to be detected in real-time and finally allowed measuring the rod stroke $s$ through the motion conversion by helical joint. The signal acquisition was obtained by using specialised software (Catman Easy - HBM Darmstadt, Germany $\left.{ }^{\circledR}\right)$ thanks to a laptop connected via the USB port.

\subsection{Experimental protocol}

Initially, the reliability of the ancillary instrument was established. The linearity and reproducibility of the strain gauge sensor, fixed onto the tensile rod (actuator), was established by using a tensile machine (Instron, Norwood, MA, USA 3366®). The kinematic detection of the rod motion $(s)$ was controlled by using a micrometer calliper.

The methodology was then evaluated ex-vivo (test-bench) by using a tensile machine (Instron, Norwood, MA, USA $3366 ®$ ) which allowed controlling displacements and loadings. The implant was located into a dedicated interface to mimic the in-vivo deployment mode. Before deployment, the implant was initially located into a hollow cylinder. The upper half cylinder was fitted to the force gauge of the tensile machine while the lower half-cylinder was fastened to the machine frame.

Three $5 \mathrm{~mm}$ diameter implants were tested in each series. In the first series of measurements, the implant opening $D(s)$ was obtained at 5 $\mathrm{mm}, 7 \mathrm{~mm}, 9 \mathrm{~mm}, 11 \mathrm{~mm}$ and $15 \mathrm{~mm} . F_{a}$ and $s$ were measured by the instrumented ancillary and the applied force $F_{p}$ was obtained by the force gauge of the tensile machine. In the second series, the force $F_{p}$ was obtained at $3 \mathrm{~N}, 50 \mathrm{~N}, 100 \mathrm{~N}, 200 \mathrm{~N}$ and $300 \mathrm{~N}$. The deployment $D(s)$ was provided by the follower-control of the tensile machine while the rod parameters $F_{a}$ and $s$, were measured by the instrumented ancillary.

The cadaveric study was carried out on lumbar and thoracic vertebral segments of normal and osteoporotic spines. Donors included one 70-year-old woman with osteoporotic vertebrae, and two 70-year-old women whose spine did not show any pathology and bone properties during surgery were classified by the surgeon as normal bone. Levels $T_{11}, T_{12}, L_{1}, L_{2}, L_{3}$, and $L_{4}$ were instrumented and all were fracture-free. Implant deployment $D(s)$ was made up to the maximal opening magnitude. The instrumented ancillary measured parameters $F_{a}$ and $s$ and the pushing force $F_{p}$ were determined by interpolation of the surface response obtained with the test-bench and completed by the resolution of Eq. (2).

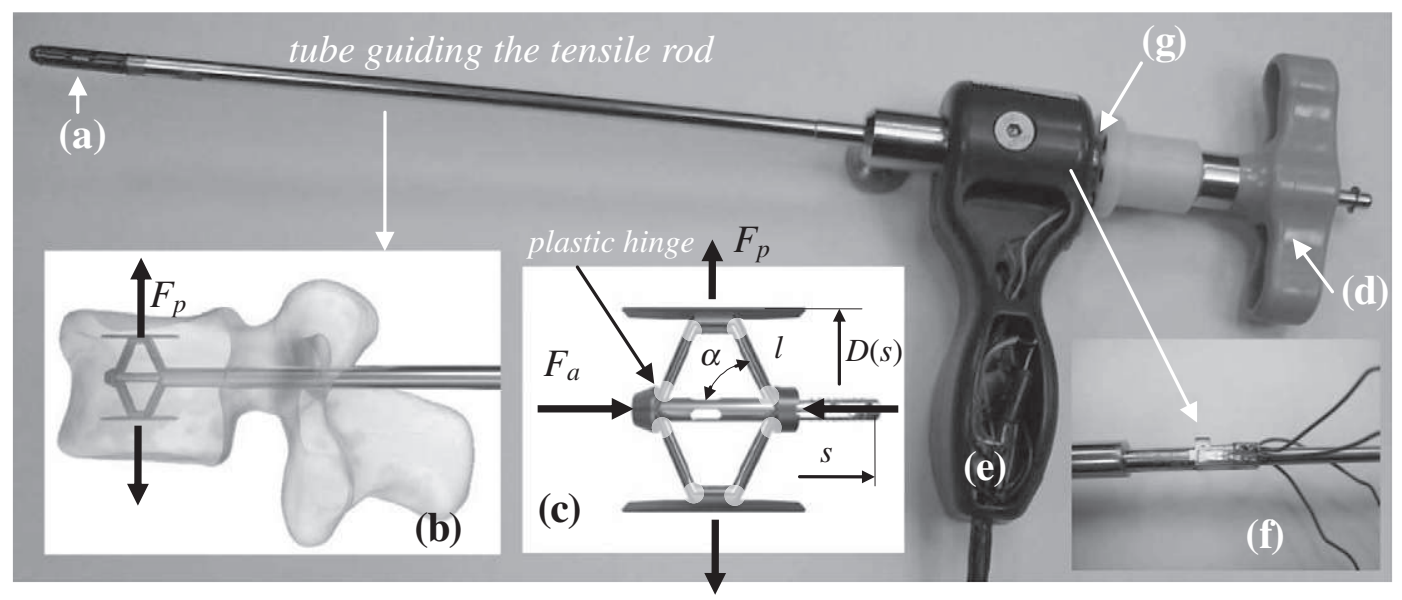

Fig. 1. Description of the implant deployment and instrumented ancillary. (a) Folded implant fixed at the rod tip before deployment (diameter $=5 \mathrm{~mm}$ ), (b) location of implant and tensile rod guiding tube into the vertebral body and pedicle respectively, (c) implant kinematic and associated forces $\left(F_{a}, F_{p}\right)$ during deployment, (d) rotating handle, (e) fixed handle, (f) rod instrumented with full bridge strain gauges, (g) rotating magnets facing the hall-effect sensor. s: rod stroke and $D(s)$ : vertical deployment of the implant. 


\section{Results}

Calibration tests with the tensile machine provided the accuracy measurement of $\pm 0.5 \%$ for $F_{a}$. The output measure of the kinematic sensor was plotted in Fig. $2 \mathrm{~b}$. At each tension-impulse $u$ (volt) detected by the hall effect detector corresponded to the increment of rod translation $c(\mathrm{~mm})$. The accuracy was $\pm 12.5 \%$.

The theoretical response surface of the implant corresponding to Eq. (1) and Eq. (2) was plotted in Fig. 2a with magnitudes of $D(s), F_{p}$ and $F_{a}$ varying up to $13 \mathrm{~mm}, 180 \mathrm{~N}$ and $2000 \mathrm{~N}$, respectively. Eq. (1) expressing $D(s)$ was plotted in Fig. 3c.

Fig. 3 summarized results obtained after the test-bench procedure. Concerning tests with controlled displacements, Fig. 3a shows 3 zones of interest of controlled displacements when $D(s)=13 \mathrm{~mm}$. In zone 1 , the implant was not in contact with the interface (i.e. free-free boundary conditions), $F_{a}$ induced the deformation of plastic hinges, and $F_{p}$ was nil. In zone 2 , contact was made, $F_{a}$ and $F_{p}$ were increasing simultaneously and proportionally during the implant deployment. Zone 3 in Fig. 3a delimited the force deployment. Fig. 3b showed the experimental surface response for controlled displacements varying from $5 \mathrm{~mm}$ to $15 \mathrm{~mm}$. The average cranio-caudal pushing force reached $400 \mathrm{~N}$.

Fig. $3 c$ showed results relative to controlled loading conditions in the range of $3 \mathrm{~N}-300 \mathrm{~N}$. This resistive force opposed to the pushing force $F_{p}$, went against the implant deployment. An attenuation of the deployment was lower than $2 \mathrm{~mm}$ even for a force up to $300 \mathrm{~N}$.

Fig. 4a showed three steps of the cadaveric implantation: initiation of implant deployment, complete deployment of implant and cement injection. In Fig. $4 \mathrm{~b}, F_{a}$ values are shown for the four implantations in osteoporotic vertebrae: $T_{11}, L_{2}, L_{3}$, and $L_{4}$. To mimic clinical settings, implantation was deliberately located close from the pedicle, under the vertebral plateau, and at the centre of the vertebral body. For $T_{12}$ and $L_{1}$ (normal bone), implants were located in half pedicle and in the centre. Results for $F_{a}, F_{p}$, $s$ and $D(s)$ are summarized in Table 1 . An evaluation of the torque $C_{h}$ applied by the operator onto the ancillary handle to actuate the tensile rod, was provided by Eq. (3) with $d \approx 2 \mathrm{~mm}$, $t \approx 0.5 \mathrm{~mm}$ and $\mu \approx 0.08$. It ranged from $0.14 \mathrm{Nm}$ to $0.37 \mathrm{Nm}$ for values of $F_{a}$ listed in Table 1 .

\section{Discussion and conclusion}

The relationship between applied forces and kinematics of the deployable implant for percutaneous vertebral augmentation was investigated. A dedicated instrumentation to measure motions and forces simultaneously was designed without modifying the surgical technique.
Force and motion were measured by strain gauges and Hall Effect sensors, respectively.

The analytical model and the test-bench showed convincing correlations. The theoretical surface response (Fig. 2a) and the experimental surface response (Fig. 3b) involving the implant opening showed identical tendencies. The theoretical and experimental pushing forces were in good agreement as shown in Fig. 3c. The force of deployment, $F_{a}$, contributed to the deformation of plastic hinges into the overall deployment of the implant. Even if their role was limited, it was taken into account by $r(s)$ in Eq. 2 . In the active zone for the vertebral body height restoration in clinics, this model established a quasiproportionality between the force actuator, the pushing force in the operative zone of the implant and the actuator kinematics.

The above results were further verified by the cadaver study for different implant loading, ranging from $3 \mathrm{~N}$ to $300 \mathrm{~N}$. Knowledge of rod translation values and applied force, derived from the verified model, could be used to estimate the kinematics and forces applied to the implant.

Experiments on normal and osteoporotic spines highlighted the significant role of bone properties and implant location in implant deployment. The recommended technique specifying the location of implant in the centre of the vertebrae required minimal forces to ensure the deployment. Applied forces were increased when the implant was located close to the endplates or the pedicles. This could be explained by the proximity of cortical bone instead of spongeous bone inside of the vertebral body. The forces were magnified up to threefold. As expected, the deployment in osteoporotic bone required less energy than that into the normal bone. This was also confirmed by the estimation of handle torque.

Limitation of using cadaveric test specimens was that in-vivo biological tissues are likely to react differently to forces subjected by the implant. Since our protocol mimicked the clinical technique, it was reasonable to confirm that the force levels were valid for clinical settings. Another limitation was that experiments were conducted on intact vertebral bodies.

It is challenging to induce fractures in vertebral bodies without causing damage to the surrounding tissues, such as the ligaments, cartilage and discs which play a significant role in the biomechanical behaviour of segments. In the clinical setting, implant deployment is likely to encounter less resistance during vertebral height restoration in acute fractures with damaged trabecular structures. As a consequence, our cadaver test showed the capability of the SpineJack ${ }^{\circledR}$ to deploy and expand in the cranio-caudal direction. This might be favourable in the clinical application.
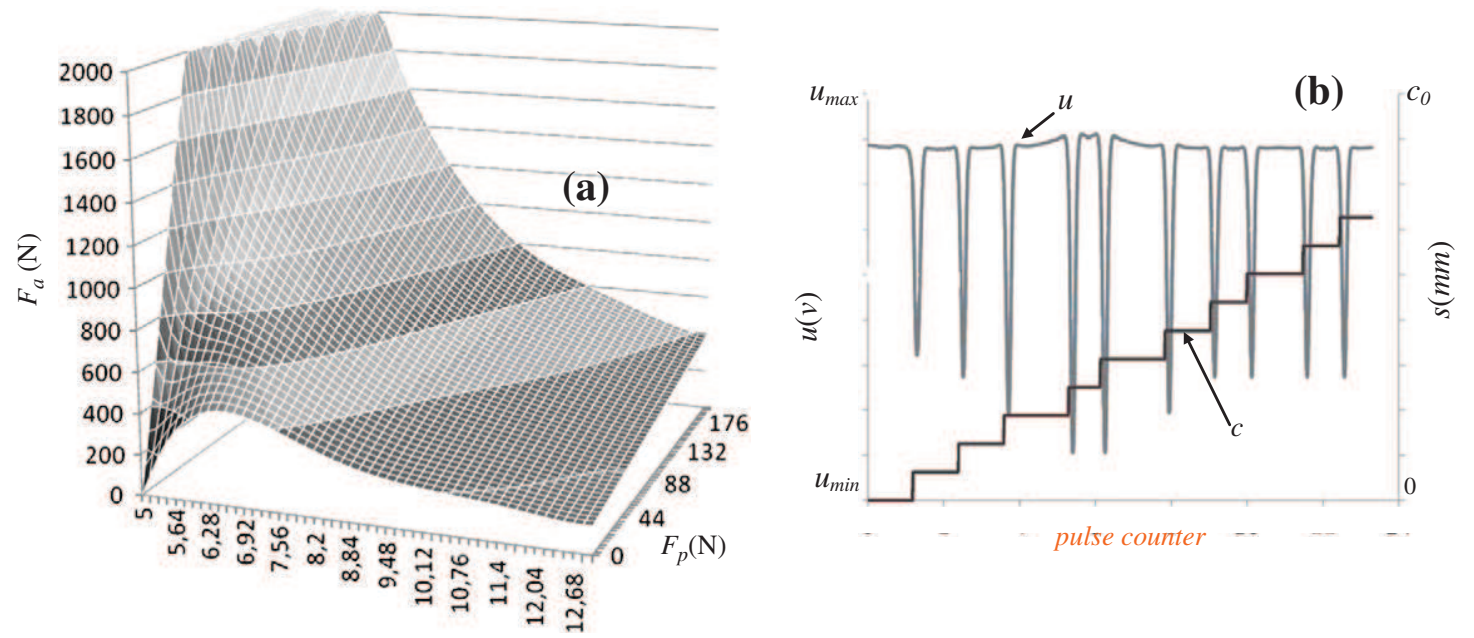

$D(s)(\mathrm{mm})$

Fig. 2. (a) Theoretical response surface of the deployable implant: $F_{a}=f\left(D(s), F_{p}, r(s)=0\right)$. (b) Ancillary kinematics: $u(v)$ : pulse counter of hall-effect sensor to detect the handle rotation, $s$ : corresponding stepwise stroke of the tensile rod (actuator). 

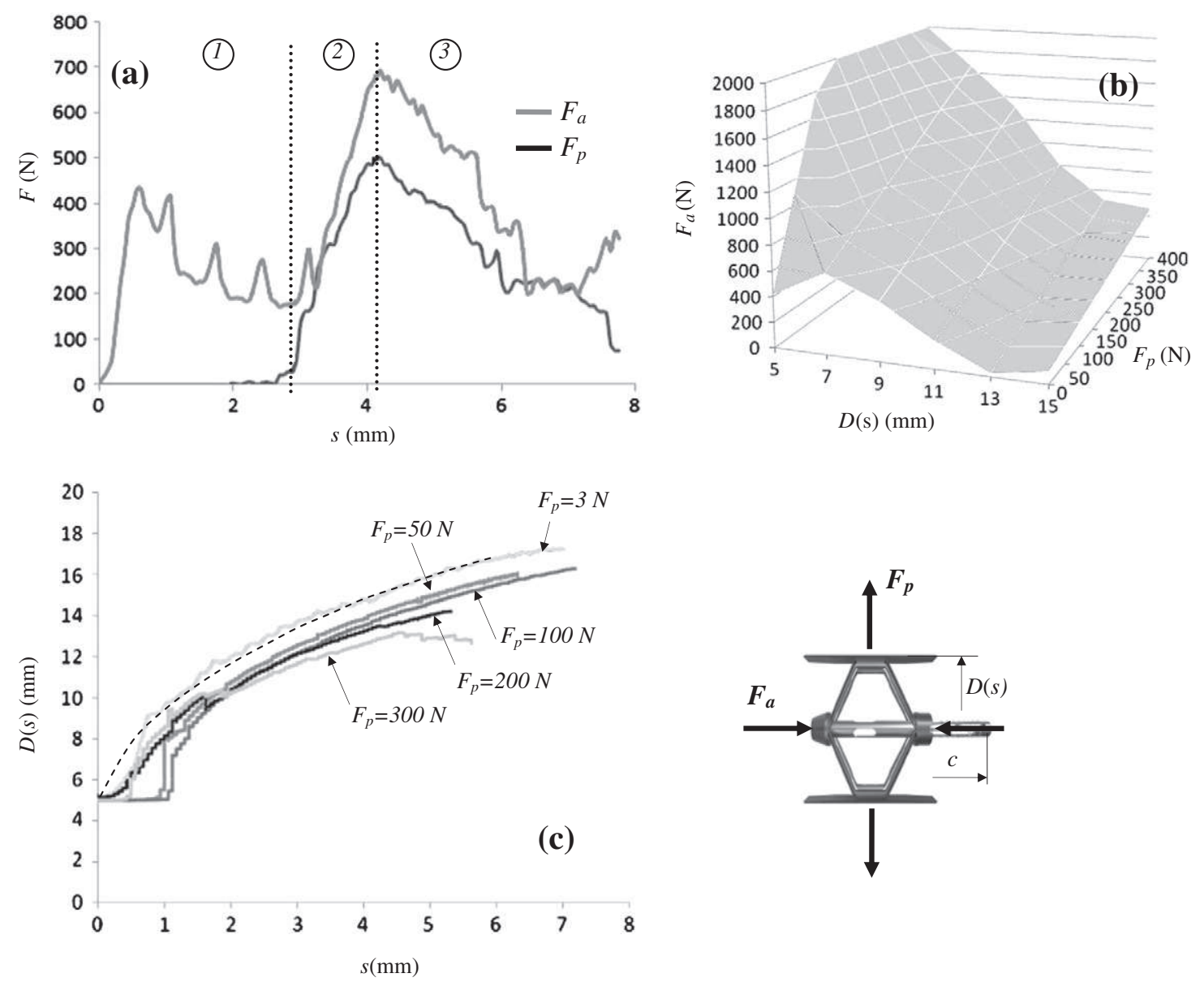

Fig. 3. Experiment on test-bench (tensile machine). (a) Measurement of forces with rod stroke $s$ : tensile force $F_{a}$ into the rod and pushing force $F_{p}$ of the implant $(D(s)=13$ mm). The implant deployment $D(s)$ was controlled at $13 \mathrm{~mm}$. (b) Response surface of the implant with monitored opening: $F_{a}=f\left(D(s), F_{p}\right)$. (c) Measurement of implant deployment with rod stroke $s$ under monitored forces: $F_{p}=3 \mathrm{~N}, 50 \mathrm{~N}, 100 \mathrm{~N}, 200 \mathrm{~N}, 300 \mathrm{~N}$. (-) theoretical model (Eq. 2, $r(s)=0$ ).
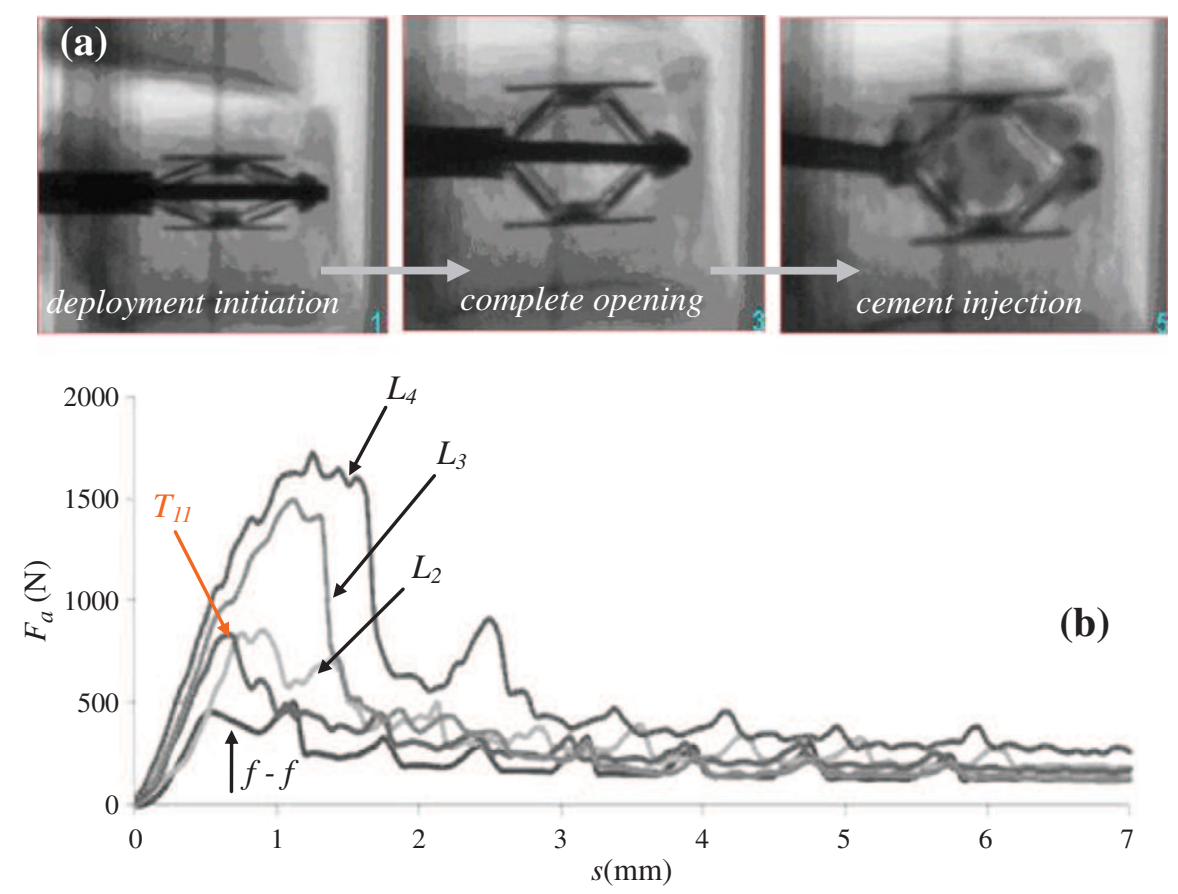

Fig. 4. Cadaver study. (a) Implant deployment into the vertebral body and cement injection. (b) Tensile force $F_{a}$ into the rod with rod stroke $s(\mathrm{~mm})$ for four vertebral levels: $T_{11}, L_{2}, L_{3}, L_{4}$ and free-free boundary conditions $(f-f)$, i.e. out of the vertebral body. 
Table 1

Results of the cadaver study. $F_{a}$ : maximal force into the actuator rod; $F_{p}$ : maximal pushing force of the implant; $\left(s, D, C_{h}\right)^{*}$ : rod stroke, implant opening and torque on the ancillary handle when $F_{a}$ was maximal.

\begin{tabular}{|c|c|c|c|c|c|c|}
\hline \multirow[b]{2}{*}{ Vertebrae } & \multicolumn{2}{|c|}{ Normal bone } & \multicolumn{4}{|c|}{ Osteoporotic bone } \\
\hline & $T_{12}$ & $L_{1}$ & $T_{11}$ & $L_{2}$ & $L_{3}$ & $L_{4}$ \\
\hline Location & Centre & $1 / 2$ Pedicle & Pedicle & Centre & Centre & Plateau \\
\hline$F_{a}(N)$ & 1651 & 1980 & 1726 & 828 & 849 & 1491 \\
\hline$F_{p}(N)$ & 99 & 164 & 108 & 22 & 24 & 81 \\
\hline$s(m m)^{*}$ & 1.55 & 3.79 & 1.26 & 0.65 & 0.83 & 1.12 \\
\hline$D(m m)^{*}$ & 9.2 & 12.7 & 8.6 & 7.4 & 7.7 & 8.3 \\
\hline$C_{h}(N m)^{*}$ & 0.29 & 0.37 & 0.3 & 0.14 & 0.15 & 0.26 \\
\hline
\end{tabular}

In conclusion, the instrumentation verified by a theoretical model allowed the objective quantification of the implant deployment and the related forces. The real-time monitoring of deployment should support the intra-operative guidance to conduct minimally invasive surgery of percutaneous vertebral augmentation. Finally, this pilot study showed a clinically relevant methodology that might contribute to improved clinical outcome.

\section{Acknowledgements}

We acknowledge the French National Agency for Research and Technology (ANRT), which provided a substantial financial support for this study. We acknowledge Professor D. Noriega, orthopaedic surgeon at the Clinico Universitaria de Vallodolid Hospital (Spain) for his contribution in the cadaveric study.

\section{References}

Galibert, P., Deramond, H., Rosat, P., Le Gars, D., 1987. Preliminary note on the treatment of vertebral angioma by percutaneous acrylic vertebroplasty]. Neurochirurgie 33,166-168.

Wong, W., Reiley, M.A., Garfin, S., 2000. Vertebroplasty/kyphoplasty. J.Women's Imaging $2,117-124$.

Knowlton, D., 2009. SpineJack lifts up fractured vertebrae. Orthopaedics, RRY Publications (http://ryortho.com/spine.php?news=88_SpineJack-Lifts-Up-Fractured-Vertebrae).

ISO 16047, 2005-2007. Fasteners - Torque/clamp force testing. American National Standards Institute (ANSI). 